\section{Predicting arterial oxygenation during one-lung anaesthesia}

\begin{abstract}
Eighty patients undergoing elective thoracotomy were studied to assess the possibility of predicting arterial oxygenation $\left(\mathrm{PaO}_{2}\right)$ during one-lung anaesthesia (OLA). The first 50 patients were studied retrospectively. The method of multiple linear regression was used to construct a predictive equation for $\mathrm{PaO}_{2}$ during OLA. Potential predictors of $\mathrm{PaO}_{2}$ during $\mathrm{OLA}$ which were considered were: age, side of operation, preoperative pulmonary flow rates, preoperative and intraoperative $\mathrm{PaO}_{2}$ during twoinng ventilation. The three most significant predictors for $\mathrm{PaO}_{2}$ during $O L A$ were: side right of operation $(P<0.05)$. preoperative $\mathrm{FEV}, \%(\mathrm{P}<0 . \mathrm{OI})$ and intraoperative $\mathrm{PaO}_{2}$ during wo-lung ventilation $(P=0.0001)$. The predictive equation for $\mathrm{PaO}_{2}$ after ten minutes of $\mathrm{OLA}$ was: $\mathrm{PaO}_{2}=100-72$ (side) -1.86 (FEV $\%$ \%) +0.75 (wo-lung) $\mathrm{PaO}_{2}$ : (for side insert Ofor left-sided thoracotomy and 1 for right-sided thoracotomy). The remaining 30 patients were studied prospectively and the predicted $\mathrm{PaO}_{2}$ correlated with the observed $\mathrm{PaO}_{2}$ after ten minutes of $\mathrm{OLA}$ ( $r=$ $0.73, \mathrm{P}<0.01$ ). Four of 30 patients had a predicted $\mathrm{PaO}_{2}$ at ten minutes of $O L A<150 \mathrm{mmHg}$. Of these, $2 / 4$ subsequently
\end{abstract}

\section{Key words}

ANAESTHESIA: thoracic;

COMPLICATIONS: hypoxaemia;

OXYGEN: monitoring;

VENTILATION: one-lung.

From the Department of Anaesthesia* and the Department of Epidemiology and Biostatistics $\dagger$, McGill University and the Division of Clinical Epidemiology, Department of Medicine, the Montreal General Hospital, Montreal, Quebec.

S. Suissa is a research scholar of the Fonds de la Recherche en Santé du Québec.

Presented in part at the annual meeting of the American Society of Anesthesiologists, Las Vegas, October, 1990 (Abstract).

Address correspondence to: Dr. P. Slinger, Montreal General Hospital, 1650 Cedar Ave., Montreal, Quebec, Canada H3G 1A4, Telephone: 514-937-6011.

Accepted for publication 13 th August, 1992.
Peter Slinger MD FRCPC,* Samy Suissa PhD, $\dagger$ William Triolet MD FRCPC

required abandonment of OLA for pulse oximetric saturation $<85 \%$. We conclude that although it is not possible to predict an individual patient's $\mathrm{PaO}_{2}$ during $\mathrm{OLA}$ with a high degree of accuracy, it is possible, before the initiation of OLA, to identify those patients whose arterial oxygenation is likely to decrease to low levels during OLA.

L'étude regroupant quatre-vingts patients au programme pour thoracotomie a pour objectif de déterminer la possibilité de prédire l'oxygénation artérielle $\left(\mathrm{PaO}_{2}\right)$ pendant l'anesthésie monopulmonaire. Pour les 50 premiers patients l'étude est rétrospective. La méthode de régression linéaire multiple est utilisée pour construire une équation prédictive pour la $\mathrm{PaO}_{2}$ pendantl'anesthésie monopulmonaire. Les critères retenus sont: l'âge, le côté opéré, les débits pulmonaires préopératoires, la $\mathrm{PaO}_{2}$ pré-et peropératoire pendant la ventilation bipulmonaire. Les trois paramètres les plus significatifs pour prévoir la $\mathrm{PaO}$ sous anesthésie monopulmonaire sont: les interventions sur le côté droit $(P<0,05)$, le VEMS préopératoire $(P<0,01)$ et la $\mathrm{PaO}_{3}$ peropératoire pendant l'anesthésie bipulmonaire $(P=$ $0,0001)$. L'équation prédictive obtenue après dix minutes de ventilation à un poumon est exprimée ainsi: $\mathrm{PaO}_{2}=100-72$ (côté) $-1,86(V E M S)+0,75 \mathrm{PaO}_{2}$ (deux poumons) (pour le côté on accorde 0 pour la thoracotomie gauche et I pour la thoracotomie droite). Les trente autres patients sont étudiés de façon prospective et la $\mathrm{PaO}_{2}$ prédite correspond a la $\mathrm{PaO}_{2}$ observee apres dix minutes de ventilation monopuimonaire $(r=0,73, P<$ $0,01)$. Après dix minutes de ventilation monopulmonaire, quatre des 30 patients ont une valeur prédite de $\mathrm{PaO}_{2}$ intérieure à 150 $\mathrm{mmHg}$. De ceux-ci, chéz deux sur quatre, la ventilation monopulmonaire est abandonnée à cause d'une saturation pulsée inférieure à $85 \%$. Nous concluons que bien qu'il soit impossible de prédire avec précision la $\mathrm{PaO}_{2}$ d'un patient donné pendant la ventilation à un poumon, on peut avant d'intier la ventilation monopulmonaire, identifier ceux parmi les patients dont l'oxygénation artérielle est susceptible de s'abaisser de façon importante.

The risk of developing hypoxaemia remains a major concern when the use of one-lung anaesthesia (OLA) is considered for thoracic surgery. ${ }^{1}$ Several factors such as hypoxic pulmonary vasoconstriction (HPV), lung collapse and gravity are known to ameliorate the decrease in 
arterial oxygen tension $\left(\mathrm{PaO}_{2}\right)$ which occurs during OLA. However, the factors which determine whether an individual patient will develop clinically important arterial oxygen desaturation during OLA have remained unclear. ${ }^{2}$ It has previously been demonstrated that it is possible to predict the $\mathrm{PaO}_{2}$ during OLA when continuous positive airway pressure (CPAP) is administered to the nonventilated (non-dependent) lung. ${ }^{3}$ This study was designed to see if a formula could be developed which would predict the $\mathrm{PaO}_{2}$ during OLA without CPAP; then to use this formula prospectively to determine its potential to identify those patients most likely to require abandonment of OLA due to unacceptably low $\mathrm{PaO}_{2}$ values (defined as an arterial oxygen saturation $<85 \%$ ).

\section{Methods}

Eighty patients undergoing elective thoracotomy for lung or oesophageal surgery were studied. The study was approved by the Ethics Committee and signed informed consent was obtained from each patient. The day before surgery, with the patient in the supine position, arterial blood was drawn for gas analysis to determine the $\mathrm{PaO}_{2}$ breathing air (air- $\mathrm{PaO}_{2}$ ). All blood gas samples were placed on ice and analyzed within $15 \mathrm{~min}$ on a Statpro-1 blood gas analyzer (Nova Biomedical, Mississauga, Ontario). Also, on the day before surgery, with the patient in the sitting position, spirometry was performed using a Spriomate AS-600 spirometer (Riko Instr. Corp., Lake Success, N.Y.) to determine the forced expiratory volume in one second $\left(\mathrm{FEV}_{1}\right)$, the forced vital capacity (FVC), and these values as a percent of predicted values (Knudson ${ }^{4}$ ).

Patients were premedicated with promethazine $50 \mathrm{mg}$ and glycopyrrolate $0.2 \mathrm{mg}$ im one hour preoperatively. After arrival in the operating room, ECG, pulse oximeter (Nellcor N-1000, Nellcor Inc., Hayward, Calif, Signal averaging time 5-7 sec.) and intravenous and intra-arterial catheters were placed. General anaesthesia was induced with fentanyl, $5 \mu \mathrm{g} \cdot \mathrm{kg}^{-1}$, thiopentone, 2 to $3 \mathrm{mg} \cdot \mathrm{kg}^{-1}$ and pancuronium, $0.08 \mathrm{mg} \cdot \mathrm{kg}^{-1}$ and maintained with isoflurane, $0.5 \%$ to $1.5 \%$ inspired concentration, in oxygen. The isoflurane dose was titrated to maintain the systolic blood pressure within $\pm 20 \%$ of the preinduction value.

After induction of anaesthesia, a left-sided doublelumen endobronchial tube was inserted. The patient was then turned to the lateral decubitus position and the double-lumen tube placement was verified and adjusted using a fibreoptic bronchoscope. The adequacy of onelung isolation was verified by observing for cessation of air flow from the non-dependent lung (ND-lung) to an underwater drain when the endobronchial cuff was inflated and only the dependent lung (D-lung) was ventilated. The lungs were ventilated with a tidal volume of $10 \mathrm{ml} \cdot \mathrm{kg}^{-1}$ during both one and two-lung ventilation. The respiratory rate was adjusted to maintain the $\mathrm{PaCO}_{2}$ between 36 and $40 \mathrm{mmHg}$.

The initial intraoperative blood gas sample was drawn 15 min after turning to the lateral position to determine the $\mathrm{PaO}_{2}$ during two-lung ventilation (two-lung $\mathrm{PaO}_{2}$ ). After the non-dependent thorax was opened, ventilation to the ND-lung was discontinued when requested by the surgeon and the ND-lung allowed to collapse by opening the appropriate lumen of the double-lumen tube to atmosphere. Repeat blood gas analysis was made 10 and $25 \mathrm{~min}$ after the start of OLA, before ligation of any major pulmonary vessels and during a period of haemodynamic stability. One lung anaesthesia was abandoned if the arterial oxygen saturation decreased to $<85 \%$ on either the pulse oximeter $\left(\mathrm{SpO}_{2}\right)$ or the blood gas resuit.

The first 50 consecutive patients were studied retrospectively and were designated Group $\mathrm{A}$. The data from these patients were analyzed by multiple linear regression between 10 and 25 min one-lung $\mathrm{PaO}_{2}$ and the following potential predictors: age, side of operation, $\mathrm{FEV}_{1}, \mathrm{FEV}_{1} \%, \mathrm{FVC}, \mathrm{FVC} \%, \mathrm{FEV}, / \mathrm{FVC}$ ratio, air- $\mathrm{PaO}_{2}$ and two-lung $\mathrm{PaO}_{2}$. Multiple linear regression simultaneously assessed the independent contribution of each predictor in explaining the variability in $\mathrm{PaO}_{2}{ }^{5}$ This method was used to construct a predictive equation for one-lung $\mathrm{PaO}_{2}$ at ten minutes by using its most highly significant independent predictors. The second group (Group B) contained 30 patients and was studied prospectively. The association between the predicted $\mathrm{PaO}_{2}$ during OLA, as derived from the Group $A$ formula, and the observed $\mathrm{PaO}_{2}$ during OLA was assessed by Pearson's correlation coefficient. The performance of the predictive equation obtained from Group $A$ was assessed by crossvalidation. ${ }^{6}$ The mean values of Groups $A$ and $B$ for all measured and documented variables were compared using two-tailed T-tests for unpaired data.

\section{Results}

Descriptive statistics for all 80 patients are shown in Table I. There were no differences between the groups for any of the measured or documented variables. One-lung anaesthesia was abandoned at an $\mathrm{SpO}_{2}<85 \%$ in 4/80 (two in Group $A$ and two in Group B) patients and the ND-lung re-inflated. This occurred between 10 and $25 \mathrm{~min}$ after the start of OLA in all four patients. Thus, one-lung $\mathrm{PaO}_{2}$ values were available for all study patients only up to ten minutes of OLA. For this reason, the ten-minute OLA values were used in the construction of the predictive model for $\mathrm{PaO}_{2}$ during OLA.

The most significant explanatory independent predictors for the $\mathrm{PaO}_{2}$ after ten minutes OLA in the Group A patients were: side of operation, $\mathrm{FEV}_{1} \%$ and two-lung $\mathrm{PaO}_{2}$. The derived predictive equation for $\mathrm{PaO}_{2}$ after ten 
TABLE I Patient data

\begin{tabular}{|c|c|c|}
\hline & Group A & Group B \\
\hline Number of patients & 50 & 30 \\
\hline Right thoracotomy & 38 & 20 \\
\hline Left thoracotomy & 12 & 10 \\
\hline Pneumonectomy & 7 & 7 \\
\hline Lobectomy & 35 & 17 \\
\hline Oesophagogastrectomy & 4 & 1 \\
\hline Other* & 4 & 5 \\
\hline Age (yr) & $60( \pm 9)$ & $65( \pm 12)$ \\
\hline $\mathrm{FEV}_{1}\left(\mathrm{~L} \cdot \mathrm{sec}^{-1}\right)$ & $2.18( \pm 0.67)$ & $2.29( \pm 0.6)$ \\
\hline $\mathrm{FEV}, \%$ & $76( \pm 23)$ & $78( \pm 17)$ \\
\hline FVC (L) & $3.03( \pm 0.84)$ & $3.29( \pm 0.86)$ \\
\hline FEV,/FVC ratio & $0.72( \pm 0.10)$ & $0.70( \pm 0.09)$ \\
\hline Air $\mathrm{PaO}_{2}(\mathrm{mmHg})$ & $81( \pm 11)$ & $78( \pm 12)$ \\
\hline Two-lung $\mathrm{PaO}_{2}$ & $466( \pm 73)$ & $439( \pm 73)$ \\
\hline One-lung $\mathrm{PaO}_{2}(10 \mathrm{~min})$ & $254( \pm 121)$ & $244( \pm 129)$ \\
\hline One-lung $\mathrm{PaO}_{2}(25 \mathrm{~min}) \dagger$ & $208( \pm 104)$ & $211( \pm 100)$ \\
\hline
\end{tabular}

*Other = Biopsy, segment/wedge resection, hiatus hernia repair. tData from only 48 patients in Group A, 28 patients in Group B. Numbers followed by parentheses represent mean ( \pm SD) values. Air $\mathrm{PaO}_{2}=$ preoperative value $\left(\mathrm{FIO}_{2}=0.21\right.$; for all other $\mathrm{PaO}_{2}$ values: $\mathrm{F}_{2}=1.0$ ).

TABLE II Predictive equation for $\mathrm{PaO}_{2}$ after ten minutes of onelung anaesthesia $\left(\mathrm{PaO}_{2}=100-72\right.$ (side) $*-1.86(\mathrm{FEV}, \%)+0.75$ (two-lung $\mathrm{PaO}_{2}$ )

\begin{tabular}{ll}
\hline Variable & $P$ value \\
\hline Side & 0.016 \\
FEV ${ }_{1} \%$ & 0.002 \\
Two-lung $\mathrm{PaO}_{2}$ & 0.0001 \\
\hline
\end{tabular}

"For side insert: 0 if left-sided thoracotomy or $\mathbf{l}$ if right-sided thoracotomy.

minutes of OLA is shown in Table II as well as the significance of each of the variables. The variance of $\mathrm{PaO}_{2}$ explained by the three factors, as measured by ${ }^{2}$, was 0.54 .

An attempt was made to improve the accuracy of the model by using various transformations for two-lung $\mathrm{PaO}_{2}$ in the predictive equation. However, the maximum increase in $r^{2}$ of the model from 0.54 to 0.56 was not felt to justify the increased mathematical complexity of the formula.

Group B patients were studied prospectively. The observed values for $\mathrm{PaO}_{2}$ after ten minutes of OLA were compared with the predicted $\mathrm{PaO}_{2}$ values generated by applying the formula derived from Group A to the Group $\mathrm{B}$ data (see Table III). There was a correlation between the observed and the predicted values $(\mathrm{r}=0.73, P<0.01)$ (Figure), which, in terms of cross-validation, is represented as $r^{2}=0.53$. Four of 30 patients had a predicted $\mathrm{PaO}_{2}<150 \mathrm{mmHg}$. Of these, $4 / 4$ had an observed $\mathrm{PaO}_{2}<$ $90 \mathrm{mmHg}$ at ten minutes and in $2 / 4$, OLA was sub-
TABLE III Example of prediction of $\mathrm{PaO}_{2}$ during one-lung anaesthesia
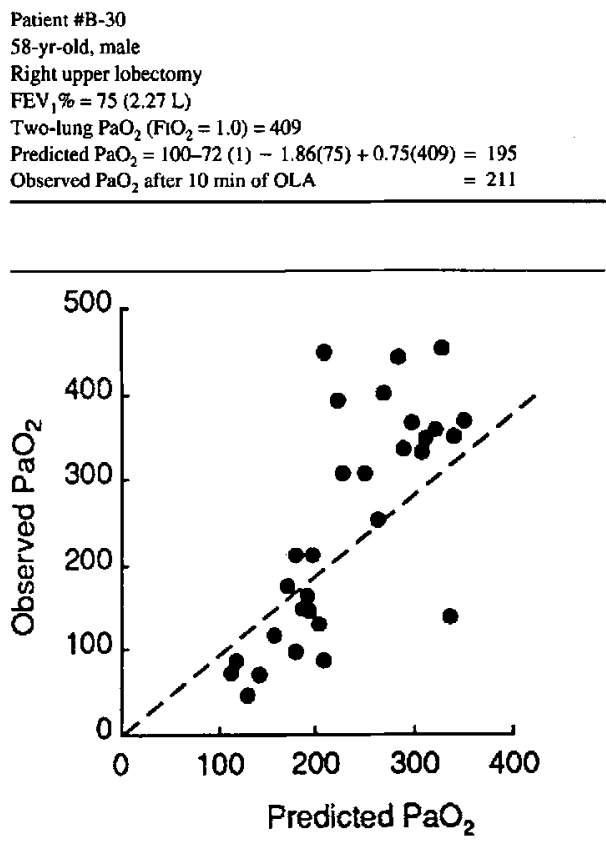

FIGURE The observed versus the predicted $\mathrm{PaO}_{2}$ values for Group B (30 patients) after ten minutes of one-lung anaesthesia. $(r=0.73$, $P<0.01$ ). Line of identity - -

TABLE IV Hypoxaemia during one-lung anaesthesia (OLA) for all 80 patients studied

\begin{tabular}{lll}
\hline $\begin{array}{l}\text { Predicted } \mathrm{PaO}_{2} \\
\text { during } \mathrm{OLA}(\mathrm{mmHg})\end{array}$ & $n$ & OLA* abandoned \\
\hline$<150$ & 10 & 4 \\
$\geq 150$ & 70 & 0
\end{tabular}

-OLA was abandoned when the arterial cxygen saturation decreased to $<85 \%$.

sequently abandoned. Based on this data set, a predicted $\mathrm{PaO}_{2}<150 \mathrm{mmHg}$ during OLA as a test for the subsequent development of hypoxaemia during OLA has a sensitivity of $2 / 2(100 \%)$ and a specificity of $26 / 28(93 \%)$.

Combined results for Group A and Group B are shown in Table IV. Among the 80 patients in the study, ten patients had a predicted $\mathrm{PaO}_{2}$ at $10 \mathrm{~min}<150 \mathrm{mmHg}$. Of these, in four cases OLA was abandoned because of hypoxaemia. No patient who had a predicted $\mathrm{PaO}_{2} \geq 150$ mmHg developed hypoxaemia during OLA. 


\section{Discussion}

This study demonstrated that it is possible to predict which patients will have a clinically important decrease of $\mathrm{PaO}_{2}$ during OLA for thoracic surgery, on the basis of data routinely available before initiation of OLA. Previously, it was thought that this was not possible.

There is no consensus on the intraoperative $\mathrm{PaO}_{2}$ value that defines hypoxaemia. Various authors have implied that the minimal acceptable level is between $50-80 \mathrm{mmHg}$ during OLA ${ }^{8-10}$ The level of critical $\mathrm{SpO}_{2}(<85 \%)$ chosen in this study corresponded with minimal observed $\mathrm{PaO}_{2}$ values down to $46 \mathrm{mmHg}$. In retrospect, this level of $\mathrm{SpO}_{2}$ is too low to be consistent with patient safety, and a critical $\mathrm{SpO}_{2}$ of $<90 \%$ would be more appropriate. The low observed $\mathrm{PaO}_{2}$ values in some patients were due to delays in the response time of the pulse oximeter ${ }^{11}$ and delays in receiving the blood gas values from the laboratory.

These results point out that the problem of hypoxaemia during OLA has not been eliminated by the advent of pulse oximetry. The reliability of $\mathrm{SpO}_{2}$ measurements ${ }^{12}$ is not yet high enough to replace the need for corroboration by blood gas sampling in clinical situations, such as OLA, where hypoxaemia is a considerable risk. For hypoxaemia, as for any anaesthetic complication, in addition to monitoring; it is useful to be able to predict which patients are most at risk for developing that complication.

The variables found to correlate with $\mathrm{PaO}_{2}$ during OLA in this study correspond to the variables found to correlate with $\mathrm{PaO}_{2}$ during OLA when CPAP of $5 \mathrm{~cm}$ of oxygen is applied to the ND-lung. ${ }^{3}$ However, in the previous study none of the patients developed hypoxaemia during OLA. For this reason it was felt necessary to perform the current study to see if the previously documented trends applied to patients when ND-lung CPAP is not, or cannot be, used. In this study, as in the previous report, the FEV, FVC ratio correlated with $\mathrm{PaO}_{2}$ after ten minutes of OLV. However, in the current study, $\mathrm{FEV}_{1} \%$ had a slightly higher correlation than FEV $/ F V C$ and was therefore used in the predictive equation.

Previously, it has not been generally appreciated that the side of surgery affects the $\mathrm{PaO}_{2}$ during OLA. The left lung normally receives $10 \%$ less perfusion than the right so it seems feasible, since the majority of shunt during OLA occurs in the ipsilateral collapsed ND-lung, that patients having left thoracotomies may have better arterial oxygenation. However, during thoracic surgery there are so many other variables that affect oxygenation that this distinction has not been clinically obvious. The statistical method used in this current investigation permits the examination of the influence of each covariate independently from the other covariates. Based on the data in this study, a patient having a left thoracotomy could be expected to have a $\mathrm{PaO}_{2} 72 \mathrm{mmHg}$ higher than a similar patient having rightsided surgery.
Patients with better preoperative pulmonary function tend to have lower $\mathrm{PaO}_{2}$ values during OLA. ${ }^{10}$ Inverse correlations between $\mathrm{FEV}_{1} \%^{13}$ or $\mathrm{FVC}^{14}$ and one-lung $\mathrm{PaO}_{2}$ have previously been reported. This current study also found that flow rates correlate inversely with $\mathrm{PaO}_{2}$ during OLA.

Clinically, we have often seen that patients with moderate or severe obstructive disease have surprisingly good oxygenation during OLA. The explanation of this paradoxical finding is not clear. There are at least three possible explanations:

First, a ND-lung effect. In a patient with obstructive disease the ND-lung may collapse more slowly. This conceivably could affect oxygenation after only ten minutes of OLA, as in this study. However, this would not explain the similar findings of Katz ${ }^{13}$ and Flacke ${ }^{14}$ when a steady state of oxygenation was assessed after $20-30 \mathrm{~min}$ of OLA.

Second, a D-lung effect. In this study the dependent lung received a relatively large tidal volume $\left(10 \mathrm{ml} \cdot \mathrm{kg}^{-1}\right)$ during OLA. The functional residual capacity (FRC) of the D-lung decreases on turning to the lateral position but then increases with the start of OLA. ${ }^{15}$ This is associated with the development of a persistent end-expiratory airflow. Patients with obstructive airways disease tend to develop a persistent end-expiratory airflow during mechanical ventilation and this correlates with the presence of intrinsic positive end-expiratory pressure (auto PEEP). ${ }^{16}$ Auto PEEP has been shown to develop in most patients during OLA. ${ }^{17}$ The effects of this auto PEEP on oxygenation during OLA have not been studied. If auto PEEP raises the mean airway pressure ( $\mathrm{Paw}$ ) in the D-lung it will tend to force blood flow back up to the ND-lung and increase shunt. However, if auto PEEP raises the FRC of the Dlung to its normal volume then pulmonary vascular resistance (PVR) in the D-lung will fall (since PVR is lowest at FRC), D-lung blood flow will increase and NDlung shunt will decrease.

Third, a redistribution of perfusion effect. It is possible that patients with obstructive lung disease could be chronically subject to a degree of hypoxic pulmonary vasoconstriction (HPV). The most important factor in decreasing ND-lung blood flow during OLA seems to be HPV.' Patients with obstructive disease and secondary pulmonary vascular changes may redistribute the perfusion between the lungs during OLA in a different fashion from those with normal lungs.

The most important predictor of $\mathrm{PaO}_{2}$ during OLA is two-lung $\mathrm{PaO}_{2}$. The two-lung $\mathrm{PaO}_{2}$ gives an indication of the respiratory system's ability to maintain ventilation and perfusion matching in the face of factors which are known to cause an imbalance such as: general anaesthesia, positive pressure ventilation, lateral position and increased inspired oxygen concentration. 
The nadir of the decrease in $\mathrm{PaO}_{2}$ values usually occurs between $20-30$ min after the onset of OLA. ${ }^{18}$ Prediction of the ten-minute OLA $\mathrm{PaO}_{2}$ value is useful because all four of the 80 patients in the study who subsequently developed hypoxaemia during OLA had both low observed and low predicted ten-minute $\mathrm{PaO}_{2}$ values. This suggests that patients who are going to develop hypoxaemia during OLA demonstrate an early trend towards arterial oxygen desaturation. No hypoxaemia occurred subsequently in patients who tolerated the first 25 min of OLA.

The predictive equation is skewed towards over-estimation of the observed $\mathrm{PaO}_{2}$ at the low end, and underestimation at the upper end of the range. There are several reasons for the inaccuracy of the model. First, many factors which effect $\mathrm{PaO}_{2}$ during OLA cannot presently be predicted clinically. These include individual variability in HPV response, the haemodynamic response to OLA, ${ }^{19}$ and inhibition of HPV by surgical trauma. ${ }^{20}$

Second, the model only predicts $\mathrm{PaO}_{2}$ at ten minutes of OLA when the arterial oxygenation has not yet reached a steady state. The model was constructed this way because after ten minutes some patients became hypoxaemic and OLA was abandoned. Thus, observed OLA $\mathrm{PaO}_{2}$ values for all patients were only available for up to ten minutes. It may be possible to achieve greater accuracy in the prediction of $\mathrm{PaO}_{2}$ using 20 or 30 min OLA data, but this would eliminate the hypoxaemic patients from the calculation. It is for these patients that this study is most useful. Thus, although it is not possible to predict an individual patient's $\mathrm{PaO}_{2}$ during $\mathrm{OLA}$ with a high degree of numerical accuracy, this model can identify, with a high level of sensitivity and specificity, those patients most likely to have extreme decreases in $\mathrm{PaO}_{2}$.

The equation derived in this study can only be applied reliably to similar patients having similar anaesthetics. The usefulness of this predictive equation for other anaesthetic techniques or in other patient populations remains to be studied.

The only previous study of a technique to identify those patients most likely to become hypoxaemic during OLA required the use of preoperative ventilation/perfusion lung scans. ${ }^{21}$ The correlation with oxygenation in that previous study $(0.73)$ was no greater than the correlation in this current study. In clinical practice only a minority of patients have had ventilation/perfusion scans at the time of thoracotomy. The advantage of the technique to predict oxygenation during OLA presented in this study is that it uses data which are available in the vast majority of thoracic surgical patients.

All anaesthetists should be aware of the factors that correlate with poorer arterial oxygenation during OLA: right-sided thoracotomy, good pulmonary flow rates and low two-lung $\mathrm{PaO}_{2}$. Based on the data in this study, it is possible to identify, before the initiation of OLA, those patients most likely to become hypoxaemic. In the highrisk patient, measures can be instituted to diminish the decrease in $\mathrm{PaO}_{2}$ during OLA. Such measures include non-dependent lung CPAP ${ }^{22}$ and lowering the concentration of volatile anaesthetics. ${ }^{23}$ Continuous positive airway pressure cannot be used prophylactically in all cases since it tends to make some surgical procedures more difficult. This applies particularly to thoracoscopic surgery, which is becoming more frequent. The ability to predict the subsequent arterial oxygenation allows the anaesthetist and surgeon to make a more rational risk/benefit assessment regarding the use of OLA during thoracic surgery and permits more controlled intraoperative management of oxygenation.

\section{Acknowledgement}

The authors thank Miss C. Colligan for her help in preparation of the manuscript.

\section{References}

1 Benumof J. Anesthesia for Thoracic Surgery. Philadelphia, PA, WB Saunders, 1987: 273.

2 Marshall B. Anesthesia for one-lung ventilation. Anesthesiology 1988; 69: 630-1.

3 Stinger P. Suissa S, Adam J, Triolet W. Predicting arterial oxygenation during one-lung ventilation with continuous positive airway pressure to the non-ventilated lung. Journal of Cardiothoracic Anesthesia 1990; 4: 436-40.

4 Knudson RJ, Lebovitz MD, Holberg CJ, Burrows $L$. Changes in the normal maximal expiratory flow-volume curve with growth and aging. Am Rev Respir Dis 1983: 127: $725 \star 34$

5 S.A.S. Users' Guide: Statistics Version 5. Cary, Ind, Statistical Analysis System Institute, 1985: 433.

6 Kerlinger FN, Pedhazure EJ. Multiple regression in behavioural research. New York, NY, Holt, 1973: 282-5.

7 Weinreich AI, Silvay G, Lumb PD. Continuous ketamine infusion for one-lung anaesthesia. Can Anaesth Soc J 1980; 27: 485-90.

8 Read RC, Friday $C D$, Eason CN. Prospective study of the Robertshaw endobronchial catheter in thoracic surgery. Ann Thorac Surg 1977; 24: 156-61.

9 Tarhan $S$, Lungborg $R O$. Effects of increased expiratory pressure on blood gas tensions and pulmonary shunting during thoracotomy with the use of the Carlens catheter. Can Anaesth Soc J 1970; 17: 4-11.

10 Kerr JH, Crampton Smith A, Prys-Roberts C, Meloche R, Foex $P$. Observations during endobronchial anaesthesia II: oxygenation. Br J Anaesth 1974; 46: 84-92.

11 Severinghaus $J W$, Naifeh $K H$. Accuracy of response of six pulse oximeters to profound hypoxia. Anesthesiology $1987 ; 67: 551-8$. 
12 Desiderio $D P$, Wong $G$, Shah $N K$. A clinical evaluation of pulse oximetry during thoracic surgery. Journal of Cardiothoracic Anesthesia 1990; 4: 30-4.

13 Katz JA, Lavem RG, Fairley HB. Thomas AN. Pulmonary oxygen exchange during endabronchial anesthesia: effects of tidal volume and PEEP. Anesthesiology 1982; 56: 164-70.

14 Flacke $J W$, Thompson DS, Read RC. Influence of tidal volume and pulmonary artery occlusion on arterial oxygenation during endobronchial anesthesia. South Med J 1976; 69: 619-26.

15 Larsson A, Malmkvist G, Werner O. Variations in lung volume and compliance during pulmonary surgery. $\mathrm{Br} \mathrm{J}$ Anaesth 1987; 59: 585-91.

16 Pepe PE, Marini $J J$. Occult positive end-expiratory pressure in mechanically ventilated patients with airflow obstruction. Am Rev Resp Dis 1982; 126: 166-70.

17 Slinger $P D$, Hickey $D R$, Lenis $S G$, Gotfried S. Intrinsic PEEP during one-lung ventilation. Anesth Analg 1989; 68: S269.

18 Benumof $J L$, Augustine SD, Gibbons JA. Halothane and isoflurane only slightly impair arterial oxygenation during one-lung ventilation in patients undergoing thoracotomy. Anesthesiology 1987; 67: 910-5.

19 Eisenkraft JB. Effects of anaesthetics on the pulmonary circulation. Br J Anaesth 1990; 65: 63-78.

20 Chen L, Williams JJ, Alexander CM, Ray RJ, Marshall C, Marshall $B E$. The effect of pleural pressure on the hypoxic pulmonary vasoconstrictor response in closed chest dogs. Anesth Analg 1988; 67: 763-9.

21 Hurford WE, Kolker AC, Strauss HW. The use of ventilation/perfusion scans to predict oxygenation during onelung anesthesia. Anesthesiology 1987; 67: 841-4.

22 Capan LM, Turndorf H, Patel C, Ramanthan S, Acinapura $A$, Chaton $J$. Optimization of arterial oxygenation during one-lung anesthesia. Anesth Analg 1980; 59: 847-51.

23 Speis $C$, Zanne $U$, Boden $G$. Different anesthetic regimens in pulmonary surgery. Anesth Analg 1991; 72: S270. 